Subscriber access provided by MPI FUR POLYMERFORSCHUNG

\title{
Communication
}

\section{A C216-Nanographene Molecule with Defined Cavity as Extended Coronoid}

\author{
Uliana Beser, Marcel Kastler, Ali Maghsoumi, Manfred Wagner, Chiara \\ Castiglioni, Matteo Tommasini, Akimitsu Narita, Xinliang Feng, and Klaus Müllen \\ J. Am. Chem. Soc., Just Accepted Manuscript • DOI: 10.1021/jacs.6b01181 • Publication Date (Web): 15 Mar 2016 \\ Downloaded from http://pubs.acs.org on March 16, 2016
}

\section{Just Accepted}

"Just Accepted" manuscripts have been peer-reviewed and accepted for publication. They are posted online prior to technical editing, formatting for publication and author proofing. The American Chemical Society provides "Just Accepted" as a free service to the research community to expedite the dissemination of scientific material as soon as possible after acceptance. "Just Accepted" manuscripts appear in full in PDF format accompanied by an HTML abstract. "Just Accepted" manuscripts have been fully peer reviewed, but should not be considered the official version of record. They are accessible to all readers and citable by the Digital Object Identifier (DOI®). "Just Accepted" is an optional service offered to authors. Therefore, the "Just Accepted" Web site may not include all articles that will be published in the journal. After a manuscript is technically edited and formatted, it will be removed from the "Just Accepted" Web site and published as an ASAP article. Note that technical editing may introduce minor changes to the manuscript text and/or graphics which could affect content, and all legal disclaimers and ethical guidelines that apply to the journal pertain. ACS cannot be held responsible for errors or consequences arising from the use of information contained in these "Just Accepted" manuscripts. 
Cycloarenes are macrocyclic conjugated compounds formed by circularly fused benzene rings, which enclose a cavity with inward-looking carbon-hydrogen bonds. The history of cycloarenes goes back to 1987, when the first example with 12 benzene rings, Kekulene, was published by Staab and Diederich. ${ }^{1}$ Numerous theoretical studies have targeted, for example cycloarene aromaticity, vibrational frequencies, and magnetic susceptibility, ${ }^{2}$ but Kekulene and $\operatorname{cyclo}[d, e, d, e, e, d, e, d, e, e]$ decakisbenzene ${ }^{3}$ were the only two physical examples. Three decades later, in 2012, the third example of cycloarene, namely septulene with 14 benzene rings, was reported by King et al. Investigations of the electronic and structural properties of these cycloarenes suggest $\pi$-electron localized sextets rather than delocalized aromatic systems, thus supporting Clar's model over the so-called Kekulé structure. ${ }^{5}$ The known cycloarenes belong to the subgroup of primitive coronoids, having a hole surrounded by single band of hexagons, as opposed to the, up till this publication, theoretical coronoids with more bands of hexagons. ${ }^{6}$ The geometry of coronoid molecules can be generally understood as polycyclic aromatic hydrocarbons (PAHs) with a cavity of at least two hexagons. ${ }^{6,7}$ Extended PAHs, such as $\mathbf{C 4 2}$ (with $42 \mathrm{sp}^{2}$ carbons; hexa-perihexabenzocoronene) $,{ }^{8} \mathbf{C 6 0},{ }^{9} \mathbf{C 9 6},{ }^{10}$ and $\mathbf{C 2 2 2},{ }^{11}$ can be regarded as nanographene molecules, which hold promise for potential (opto-)electronic applications, ${ }^{12}$ and also serve as defined model structures of graphene. ${ }^{13}$ Recently, graphene with regular pores, which is called graphene nanomesh (GNM), has been

\begin{abstract}
We describe the first coronoid nanographene
C216-molecule. As an extended polycyclic aromatic hydrocarbon (PAH) containing a defined cavity, our molecule can the physical and chemical properties of graphene. Along the pathway of an eight-step synthesis including Yamamoto-type cyclization followed by six-fold Diels-Alder cycloaddition, final step. The defined molecular structure with a cavity was
unambiguously validated by MALDI TOF mass spectrometry and FTIR, Raman, und UV-Vis absorption spectroscopy coupled with DFT simulations.
\end{abstract}
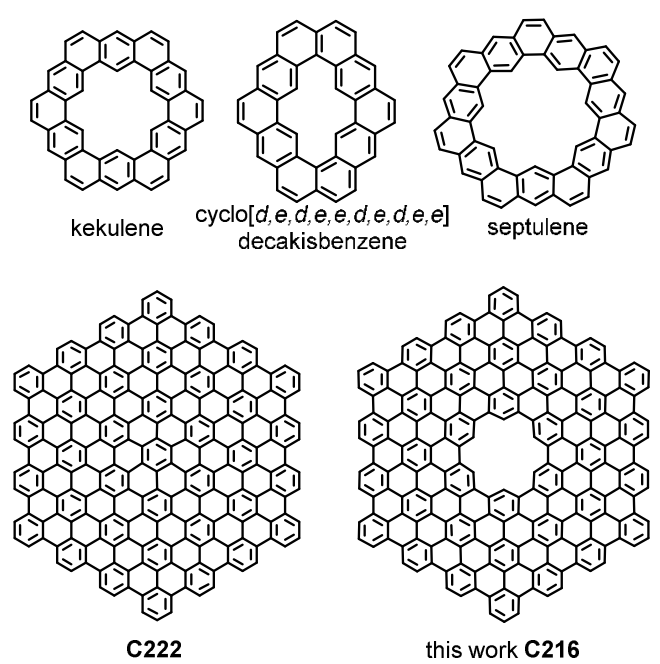

FIGURE 1. Structures of Kekulene, cyclo[d,e,d,e,e,d,e,d,e, e]decakisbenzene, septulene, $\mathbf{C}_{222}$, and coronoid $\mathbf{C}_{216}$.

demonstrated to have an open band gap, in contrast to zero-band gap graphene, highlighting the significant influence of the pore on the electronic features. ${ }^{14}$ The band gap of GNMs can be tuned by the diameter and density of the holes, showing p-type semiconducting properties. ${ }^{15}$ The formation of coronoids by introducing a defined cavity in nanographene molecules could thus be an efficient approach to modulate their optical and electronic properties without changing their external structures. Nevertheless, to the best of our knowledge, coronoid PAHs with more than one band of annelated rings have never been synthesized. Here, we report the first extended coronoid C216, containing $216 \mathrm{sp}^{2}$ carbons, which can be viewed as $\mathbf{C 2 2 2}$ with a "hole" of approximately 0.6 $\mathrm{nm}$ (Figure 1). The structure of $\mathbf{C 2 1 6}$ was unambiguously verified by a combination of matrix-assisted laser desorption/ionization time-of-flight (MALDI-TOF) mass spectrometry (MS) and FTIR, Raman, and UV-Vis absorption spectroscopic analyses, which were supported by theoretical studies. In particular, UV-Vis absorption spectroscopy and density functional theory (DFT) calculations on C216 and $\mathbf{C 2 2 2}$ elucidated considerable effects of the 
SCHEME 1. Synthetic rout towards coronoid $\mathbf{C 2 1 6}^{a}$

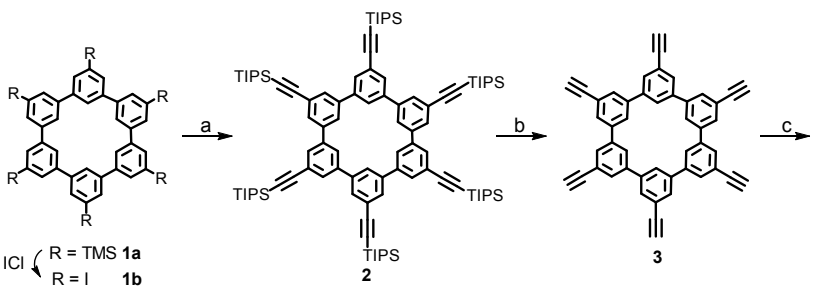

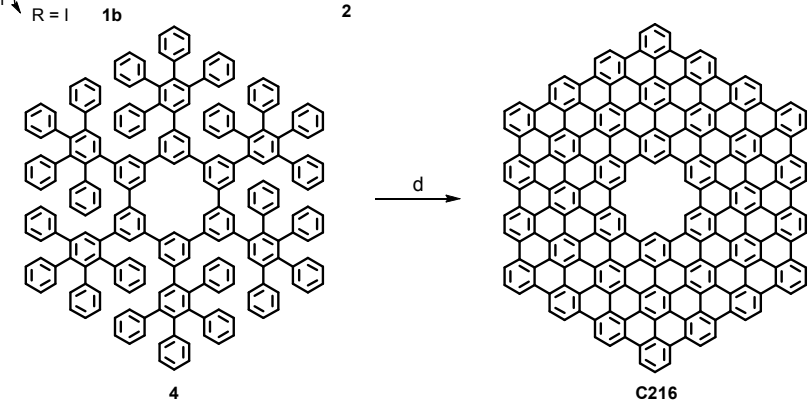

${ }^{a}$ Reagents and conditions: a) $\mathrm{CuI}, \mathrm{PPh}_{3}, \mathrm{Pd}\left(\mathrm{PPh}_{3}\right)_{4}$, TIPSacetylene, piperidine, 62\%; b) TBAF, THF, 78\%; c) 2,3,4,5tetraphenyl-cyclopenta-2,4-dienone, o-xylene, 66\%; d) $\mathrm{FeCl}_{3}$, $\mathrm{DCM} / \mathrm{CH}_{3} \mathrm{NO}_{2}, 84 \%$.

cavity on their (opto-)electronic properties, including a sizeable blue-shift of the absorption maximum of $\mathbf{C 2 1 6}$ and an increase of the HOMO-LUMO gap, compared with that of C222 (DFT: 0.4 $\mathrm{eV})$.

The synthesis of coronoid C216 was carried out as shown in Scheme 1. 5,5',5',5,', 5,',',5,',',-Hexa-iodo-hexa-m-phenylene 1b was prepared as previously reported, ${ }^{16}$ through nickel $(0)$ mediated Yamamoto-type cyclization of 5,3"-dibromo-3,5',5"-tristrimethylsilyl-[1,1';3',1"]terphenyl, giving the hexatrimethylsilylanaloge 1a, followed by a treatment with iodine monochloride. The extension of $\mathbf{1 b}$ to polyphenylene dendrimer $\mathbf{4}$, which serves as the precursor of C216, was started with six-fold HagiharaSonogashira cross coupling with tri(iso-propyl)silyl (TIPS)acetylene to afford hexakis-tri(iso-propyl)silylethynyl-hexa- $m$ phenylene cycle $2 .{ }^{17}$ Subsequently, deprotection of $\mathbf{2}$ with tetra- $n$ butylammonium fluoride (TBAF) yielded hardly soluble hexaethynyl-cyclohexa-m-phenylene $\mathbf{3}$, which was subjected to microwave-assisted six-fold Diels-Alder cycloaddition with 2,3,4,5tetraphenylcyclopenta-2,4,-dienone to afford precursor 4. Polyphenylene $\mathbf{4}$ was purified via preparative recycling gel permeation chromatography (GPC) and unambiguously characterized by ${ }^{1} \mathrm{H}$ and ${ }^{13} \mathrm{C}$ NMR, H-H COSY(H-H correlation spectroscopy), H-H NOESY (H-H nuclear overhauser enhancement spectroscopy), H$\mathrm{H}$ TOCSY (H-H total correlation spectroscopy) and highresolution MALDI-TOF MS (Figures 2a, S4, S5-S9). All the proton signals could be assigned with the help of 2D NMR spectroscopy verifying the structure of $\mathbf{4}$. Finally, precursor 4 was "planarized" into C216 through oxidative cyclodehydrogenation using iron (III) chloride. The cyclodehydrogenation of dendritic precursors has been extensively studied over the last two decades, which allowed for the synthesis of a number of PAHs, including $\mathbf{C 2 2 2}$ as the largest example up to date. ${ }^{18}$ The cyclodehydrogenation of precursor 4 was initially attempted with 5 equivalents of iron (III) chloride per hydrogen to be removed $(5$ eq./H), but MALDI-TOF MS analysis indicated that the planarization was not complete, apparently stalling with 3 bonds missing, even after stirring for 3 days. The loading of iron (III) chloride was thus increased to $7.5 \mathrm{eq} . / \mathrm{H}$, which led to the successful formation of C216 after stirring for 3 days, as verified by MALDI-TOF MS analysis showing a peak at $\mathrm{m} / z=2640.3835$, consistent with the expected mass of C216, i.e., 2640.3756 (Figure 2b). However, partial chlorination could not be suppressed, similar to the previous synthesis of extended nanographenes. ${ }^{11}$ The isotopic distribution observed for the obtained $\mathbf{C 2 1 6}$ sample was in perfect agreement with the pattern simulated for $\mathrm{C}_{216} \mathrm{H}_{48}$, corroborating the complete cyclodehydrogenation (Figure 2b, inset). Coronoid C216 was not soluble in organic solvents, which precluded characterization by NMR spectroscopy or growth of single crystals. Nevertheless, further structural proof could be obtained by microIR and micro-Raman spectroscopic analyses on powder samples of C216. Figure 3a shows the three characteristic IR bands associated to the $\mathrm{C}-\mathrm{H}$ out-of-plane bending vibrations observed in C216. These are well accounted by DFT calculations which also reveal the associated nuclear displacements, localized on the three kinds of $\mathrm{C}-\mathrm{H}$ bonds of $\mathbf{C 2 1 6}$ (see supporting information for details). The band measured at $786 \mathrm{~cm}^{-1}$ is mostly due to the collective bending vibration of the $\mathrm{CH}$ bonds located at the six outer vertexes of $\mathbf{C 2 1 6}$ and could be named as a TRIO mode, the band at $802 \mathrm{~cm}^{-1}$ is mostly due to the bending of the $\mathrm{C}-\mathrm{H}$ bonds located along the six outer edges of $\mathbf{C 2 1 6}$ (DUO mode). ${ }^{19}$ Most importantly, the band at $857 \mathrm{~cm}^{-1}$ is due to the collective bending of the $\mathrm{C}-\mathrm{H}$ bonds at the inner edge of the hole in $\mathbf{C 2 1 6}$ and thus constitutes a characteristic IR marker of this peculiar feature of the molecule. Although it is not conclusively mentioned in the literature, the "hole marker" peaks can also be found in the FTIR spectra of Kekulene and septulene. ${ }^{4,20}$ The Raman spectrum of C216 in the solid state (Figure 3c) shows the main expected features of graphitic molecules, namely a structured $\mathrm{D}$ and $\mathrm{G}$ band. ${ }^{21}$ The comparison between DFT calculations for C222 and C216 highlights the presence of one mode in the $\mathrm{D}$ region (labeled with a star in Figure 3c)

a)

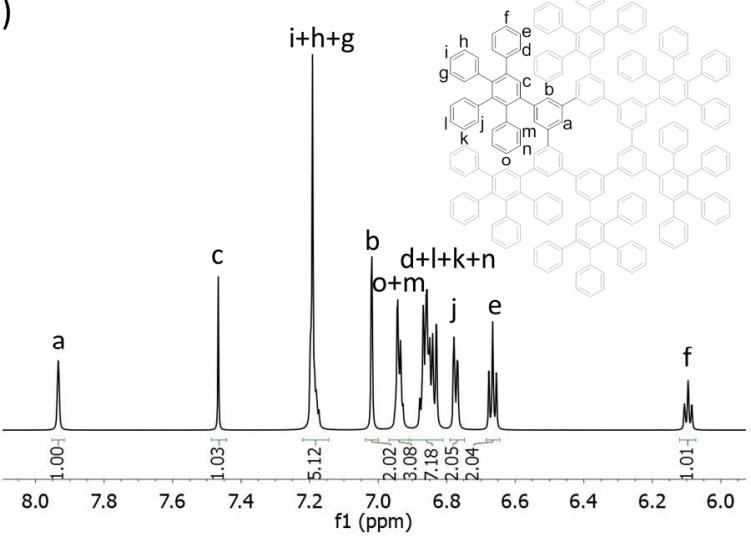

b)

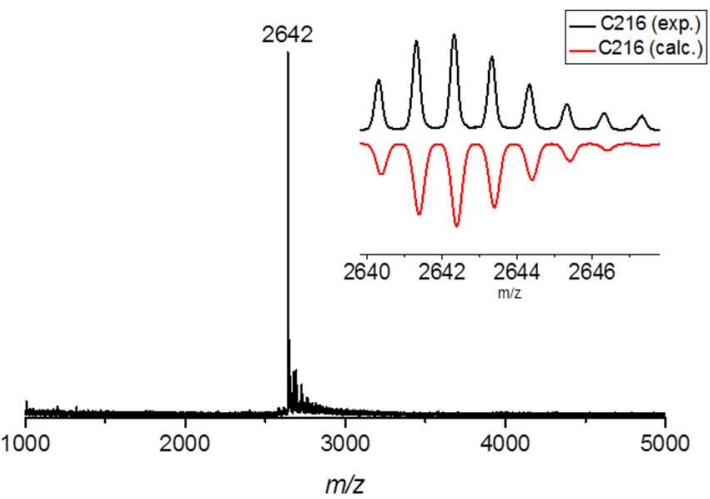

FIGURE 2. a) ${ }^{1} \mathrm{H}$ NMR spectra of 4, b) MALDI-TOF spectrum of C216; inset: magnified spectrum showing isotopic distribution. 
whose nuclear displacements are more localized at the hole edge. Such a prominent Raman line, which is also experimentally observed, is not seen in $\mathbf{C 2 2 2}$ and can be taken as a signature of the hole. Further signature features are identified in the low wavenumber region of the Raman spectrum, among which DFT calculations reveal the breathing mode of the hole (A-mode, Fig 3b). This is due to the contribution of two very close totally symmetric modes involving the collective contraction of the C-C bonds nearby the hole accompanied by the collective stretching of the outer C-C bonds.

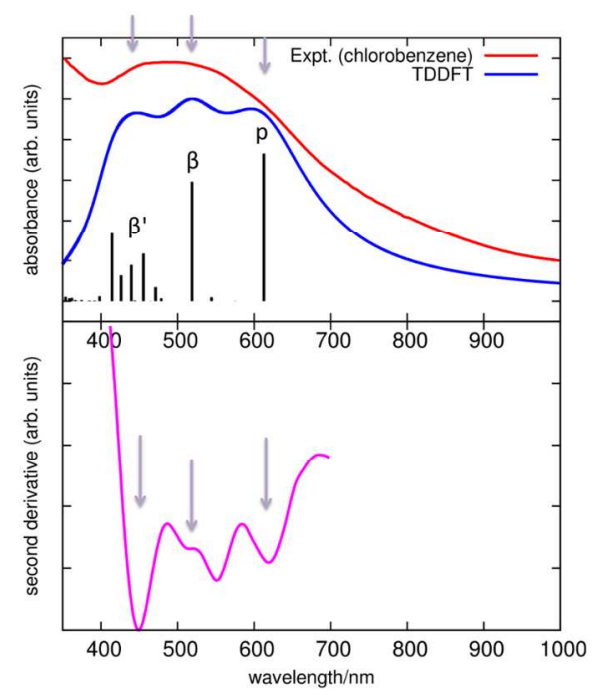

FIGURE 4. UV-Vis absorption spectrum of C216 in chlorobenzene suspension (top) with its second derivative (bottom). The arrows indicate the positions of the transitions determined by TD-DFT at the $\mathrm{B}_{3} \mathrm{LYP} / 6-31 \mathrm{G}(\mathrm{d}, \mathrm{p})$ level, which are also shown with black sticks whose length is proportional to the oscillator strength. The simulated absorption profile from TD-DFT transitions is also reported for comparison with experimental data.

Albeit the insoluble nature of coronoid C216, its UV-Vis absorption spectrum could be measured from a chlorobenzene suspension by using an integration sphere (Figure 4). A closer look at the broad, nearly featureless absorption profile, by taking the second derivative, displayed subtle changes in the slope at 620,520 , and $450 \mathrm{~nm}$, which might correspond to different optical transitions (bottom panel of Figure 4). TD-DFT calculations on C216 at the B3LYP/6-31G(d,p) level indeed revealed doubly degenerate transitions at 613 and 519 as well as a cluster at $455,439,426$, and $414 \mathrm{~nm}$. This respectively corresponds to $\mathrm{p}$-, $\beta$-, and $\beta$ '-bands in Clar's notation, and are consistent with the positions estimated from the experimental spectrum. In contrast, the absorption spectrum of $\mathbf{C 2 2 2}$ features a broad absorption with maximum at $\sim 750$ $\mathrm{nm} .{ }^{11}$ TD-DFT calculation reveals that the p-band, which is generally the one most related to the HOMO-LUMO transition in PAHs, blue-shifts by about $100 \mathrm{~nm}(0.3 \mathrm{eV})$, when comparing C222 (714 nm) with C216 (613 nm).

Furthermore, DFT calculations on coronoid $\mathbf{C 2 1 6}$ and $\mathbf{C 2 2 2}$ gave more insight into the effect of the "hole". The HOMO and LUMO

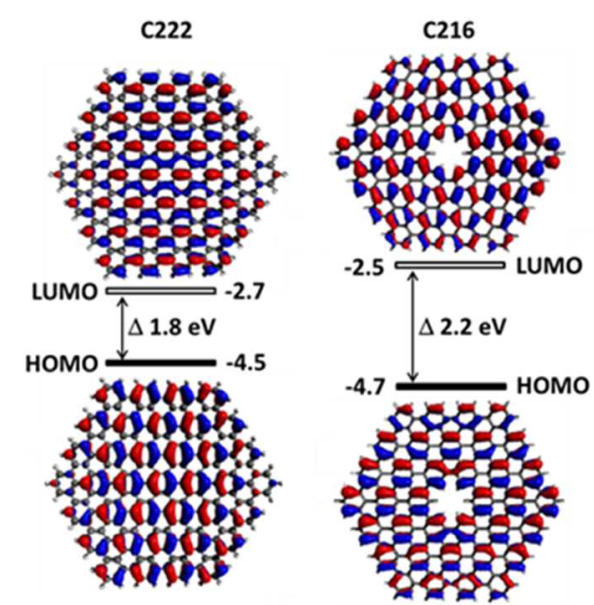

FIGURE 5. HOMO and LUMO levels and HOMO-LUMO gap for $\mathbf{C}_{222}$ and $\mathbf{C}_{216}$ calculated by DFT at the B3 $2 \mathrm{LY} / 6-31 \mathrm{G}(\mathrm{d}, \mathrm{p})$ level (see supporting information for details).

levels of $\mathbf{C 2 1 6}$ were revealed to be at -4.7 and $-2.5 \mathrm{eV}$, respectively, with a HOMO-LUMO gap of $2.2 \mathrm{eV}$ while the HOMO and LUMO levels of $\mathbf{C 2 2 2}$ are reported to be at -4.5 and $-2.7 \mathrm{eV}$, respectively, with a HOMO-LUMO gap of $1.8 \mathrm{eV} .^{22}$ This result demonstrated that the introduction of the hole in the $\mathbf{C 2 2 2}$ disk increased the HOMO-LUMO gap by $0.4 \mathrm{eV}$ (see Figure 5: de- 
crease of the HOMO and increase of the LUMO by $0.2 \mathrm{eV}$ ), which is in agreement with the UV-Vis measurement (see supporting information for the theoretical details, including the comparison of B3LYP, PBE0, and PBE functionals).

In summary, the synthesis and characterization of the first multilayer coronoid $\mathbf{C 2 1 6}$ have been described. Investigations by MALDI-TOF MS and IR, Raman, and UV-Vis absorption spectroscopy combined with (TD-)DFT calculations provided an explicit structure proof. The FTIR and Raman spectra were starkly modulated by the introduction of the cavity, compared to those of the parent C222 disk. Notably FTIR analysis of coronoid C216 revealed a finger-print peak from $\mathrm{C}-\mathrm{H}$ bonds inside the cavity, which can serve as a "hole marker". Furthermore, the formation of coronoids offers a new approach to fine-tune the (opto-) electronic properties of nanographene molecules, as demonstrated by the increase of the HOMO-LUMO gap from C222 to C216. Such coronoids can also serve as model structures of GNMs, which would help elucidate the exact effect of the cavity on the graphene structure.

\section{ASSOCIATED CONTENT}

\section{Supporting Information}

Experimental procedure, NMR and HR MALDI-TOF MS spectra, and the theoretical details. The material is available free of charge via the Internet at

\section{AUTHOR INFORMATION}

\section{Corresponding Author}

muellen@mpip-mainz.mpg.de

\section{Present Addresses}

${ }^{\S}$ BASF SE, 67056 Ludwigshafen, Germany

\section{Notes}

The authors declare no competing financial interests.

\section{ACKNOWLEDGMENT}

We are grateful for the financial support from the European Research Council grant on NANOGRAPH, DFG Priority Program SPP 1459, European Commission through the FETProactive Project "MoQuaS", contract N.610449, and Graphene Flagship (No. CNECT-ICT-604391). We thank Wen Zhang for high-resolution MALDI-TOF MS analysis and Prof. Mark D. Watson for insightful comments on the manuscript.

\section{REFERENCES}

(1) Staab, H. A.; Diederich, F. Chem. Ber. 1983, 116, 3487.

(2) a) Dias, J. R. J. Phys. Chem. A 2008, 112, 12281; b) Miyoshi, H.; Nobusue, S.; Shimizu, A.; Tobe, Y. Chem. Soc. Rev. 2015, 44, 6560.

(3) Funhoff, D. J. H.; Staab, H. A. Angew. Chem. Int. Ed. 1986, 25, 742. (4) Kumar, B.; Viboh, R. L.; Bonifacio, M. C.; Thompson, W. B.; Buttrick, J. C.; Westlake, B. C.; Kim, M.-S.; Zoellner, R. W.; Varganov, S. A.; Mörschel, P.; Teteruk, J.; Schmidt, M. U.; King, B. T. Angew. Chem. Int. Ed. 2012, 51, 12795.

(5) a)Aihara, J.-i.; Makino, M.; Ishida, T.; Dias, J. R. J. Phys. Chem. A 2013, 117, 4688; b) Hajgató, B.; Deleuze, M. S.; Ohno, K. Chem. Eur. J. 2006, 12, 5757.

(6) Cyvin, S. J.; Brunvoll, J.; Cyvin, B. N. J. Chem. Inform. Comput. Sci. 1990, 30, 210.

(7) a) Cyvin, S. J.; Brunvoll, J.; Cyvin, B. N. In Theory of Coronoid Hydrocarbons; Springer Berlin Heidelberg: 1991; Vol. 54, p 13; b)
Brunvoll, J.; Cyvin, B. N.; Cyvin, S. J.; Gutman, I.; Tošić, R.; Kovačević, M. J. Mol. Struc.: THEOCHEM 1989, 184, 165.

(8) Kubel, C.; Eckhardt, K.; Enkelmann, V.; Wegner, G.; Müllen, K. J. Mater. Chem. 200o, 10, 879.

(9) Feng, X.; Liu, M.; Pisula, W.; Takase, M.; Li, J.; Müllen, K. Adv. Mater. 2008, 20, 2684.

(10) Tomović, Ž.; Watson, M. D.; Müllen, K. Angew. Chem. Int. Ed. 2004, 43, 755 .

(11) Simpson, C. D.; Brand, J. D.; Berresheim, A. J.; Przybilla, L.; Räder, H. J.; Müllen, K. Chem. Eur. J. 20o2, 8, 1424.

(12) a) Laschat, S.; Baro, A.; Steinke, N.; Giesselmann, F.; Hägele, C.; Scalia, G.; Judele, R.; Kapatsina, E.; Sauer, S.; Schreivogel, A.; Tosoni, M. Angew. Chem. Int. Ed. 2007, 46, 4832; b) Schmidtke, J. P.; Friend, R. H.; Kastler, M.; Müllen, K. J. Chem. Phys. 20o6, 124, 174704; c) Debad, J. D.; Morris, J. C.; Magnus, P.; Bard, A. J. J. Org. Chem. 1997, 62, 530; d) Pisula, W.; Menon, A.; Stepputat, M.; Lieberwirth, I.; Kolb, U.; Tracz, A.; Sirringhaus, H.; Pakula, T.; Müllen, K. Adv. Mat. 2005, 17, 684 .

(13) a) Morita, Y.; Suzuki, S.; Sato, K.; Takui, T. Nat Chem 2011, 3, 197; b) Pisula, W.; Feng, X.; Müllen, K. Chem. Mat. 2011, 23, 554; c) Banerjee, S.; Bhattacharyya, D. Comput. Mater. Sci. 2oo8, 44, 41; d) Ball, M.; Zhong, Y.; Wu, Y.; Schenck, C.; Ng, F.; Steigerwald, M.; Xiao, S.; Nuckolls, C. Acc. Chem. Res. 2015, 48, 267; e) Kastler, M.; Schmidt, J.; Pisula, W.; Sebastiani, D.; Müllen, K. J. Am. Chem. Soc. 2006, 128, 9526.

(14) a)Zeng, Z.; Huang, X.; Yin, Z.; Li, H.; Chen, Y.; Li, H.; Zhang, Q.; Ma, J.; Boey, F.; Zhang, H. Adv. Mat. 2012, 24, 4138; b) Liang, X.; Jung, Y.-S.; Wu, S.; Ismach, A.; Olynick, D. L.; Cabrini, S.; Bokor, J. Nano Lett. 2010, 10, 2454; c) Bai, J.; Zhong, X.; Jiang, S.; Huang, Y.; Duan, X. Nat Nano 2010, 5, 190; d) Yang, J.; Ma, M.; Li, L.; Zhang, Y.; Huang, W.; Dong, X. Nanoscale 2014, 6, 13301; e) Zhao, Y.; Hu, C.; Song, L.; Wang, L.; Shi, G.; Dai, L.; Qu, L. Energy Environ. Sci. 2014, 7, 1913; f) Ning, G.; Fan, Z.; Wang, G.; Gao, J.; Qian, W.; Wei, F. Chem. Comm. 2011, 47, 5976; h) Süle, P.; Szendrö, M.; Magda, G. Z.; Hwang, C.; Tapasztó, L. Nano Lett. 2015, 15(12), 8295-8299 ; j) Robertson, A. W.; Lee, G.-D.; He, K.; Gong, C.; Chen, Q.; Yoon, E.; Kirkland, A. I.; Warner, J. H. ACS Nano 2015, 9(12), 11599-11607.

(15) a) Jariwala, D.; Srivastava, A.; Ajayan, P. M. J. Nanosci. Nanotechnol. 2011, 11, 6621; b) Wang, M.; Fu, L.; Gan, L.; Zhang, C.; Rümmeli, M.; Bachmatiuk, A.; Huang, K.; Fang, Y.; Liu, Z. Sci. Rep. 2013, 3 .

(16) Pisula, W.; Kastler, M.; Yang, C.; Enkelmann, V.; Müllen, K. Chem. Asian J. 2007, 2, 51.

(17) Wu, J.; Watson, M. D.; Zhang, L.; Wang, Z.; Müllen, K. J. Am. Chem. Soc. 2004, 126, 177.

(18) a) Wu, J.; Tomović, Ž.; Enkelmann, V.; Müllen, K. JOC 2004, 69, 5179; b) Iyer, V. S.; Wehmeier, M.; Brand, J. D.; Keegstra, M. A.; Müllen, K. Angew. Chem. Int. Ed. 1997, 36, 1604; Wu, J.; Pisula, W.; Müllen, K. Chemical Reviews 2007, 107, 718; Narita, $\quad$ A.; Wang, X.-Y.; Feng, X.; Mullen, K. Chem. Soc. Rev. 2015, 44, 6616. (19) Tommasini, M.; Lucotti, A.; Alfè, M.; Ciajolo, A.; Zerbi, G. Spectrochim. Acta Mol. Biomol. Spectrosc., 2016, 152, 134.

(20) Balm, S. P.; Kroto, H. W. Mon. Not. R. Astron. Soc., 1990, 245, 193.

(21) Maghsoumi, A.; Brambilla, L.; Castiglioni, C.; Müllen, K.; Tommasini, M. J. Raman Spectrosc. 2015, 46, 757.

(22) Moran, D.; Stahl, F.; Bettinger, H. F.; Schaefer, H. F.; Schleyer, P. v. R. J. Am. Chem. Soc. 2003, 125, 6746. 


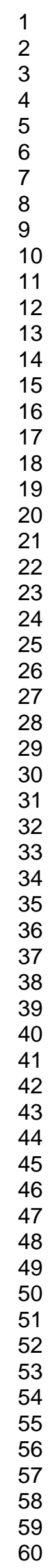

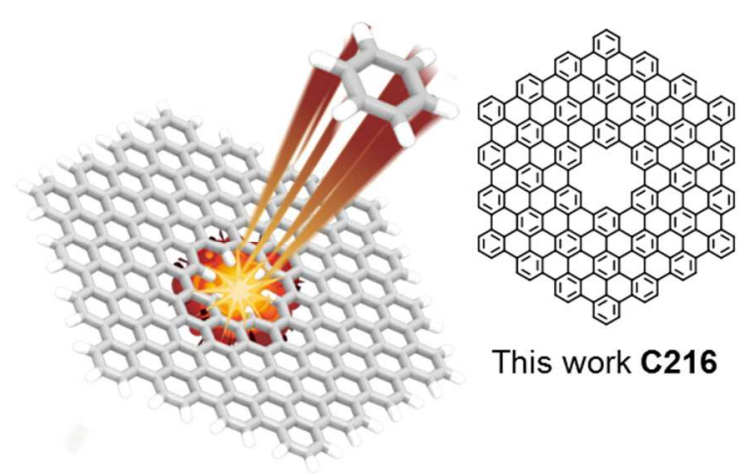

